\title{
Medical Quiz: Image
}

\author{
Islam $\mathrm{MR}^{\mathrm{a}}$, Khan $\mathrm{SA}^{\mathrm{b}}$
}

(BIRDEM Med J 2019; 9(1): )

\section{Case Scenario}

A 35- year- old diabetic gentleman got admitted in BIRDEM General Hospital with the complaints of back pain for 1 month which was gradual in onset, progressive, constant, more marked at night, worsened by movement and relieved little by rest or analgesics. He also mentioned about gradually worsening weakness and numbness of legs together with recent onset poor flow of urine and constipation for 2 weeks. Moreover, he informed about high grade intermittent fever for last 2 months for which he took different antibiotics with partial recovery. He did not give any history of trauma, fall, headache, seizure, dysarthria, dysphagia, weight loss, anorexia, cough or rash or any contact with known TB patient. On examination, he was ill looking with normal vital parameters. He had spastic paraparesis, hyperreflexia (knee and ankle) with B/L extensor plantar responses. He also had right grip weakness. All sensory modalities were reduced at right C8/T1 dermatomal level. There was spinal tenderness as well without any deformity. Rest of the clinical examination was normal. Routine investigations showed that WBC count was 14000/cumm, ESR: $90 \mathrm{~mm}$ in $1^{\text {st }}$ hour, CRP: 36ng/ml, normal renal and liver function and normal urine R/M/E. CXR P/A view was normal with negative MT. Blood C/S revealed growth of Salmonella Typhi.

MRI of dorsal spine is available:

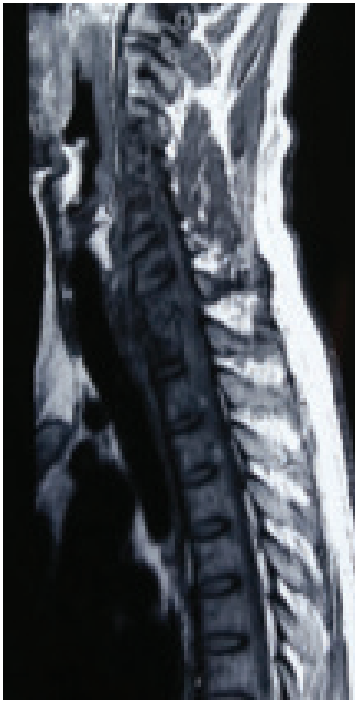

Fig.-1

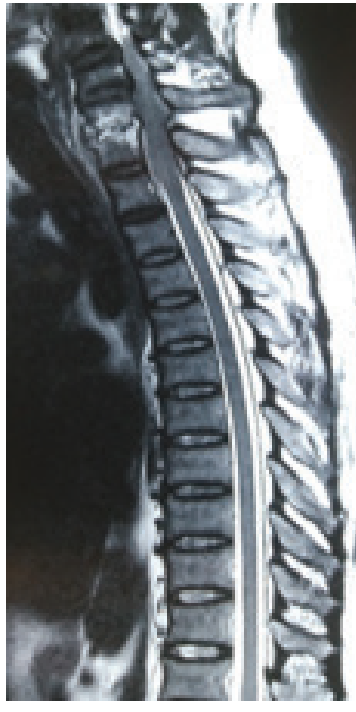

Fig.-2

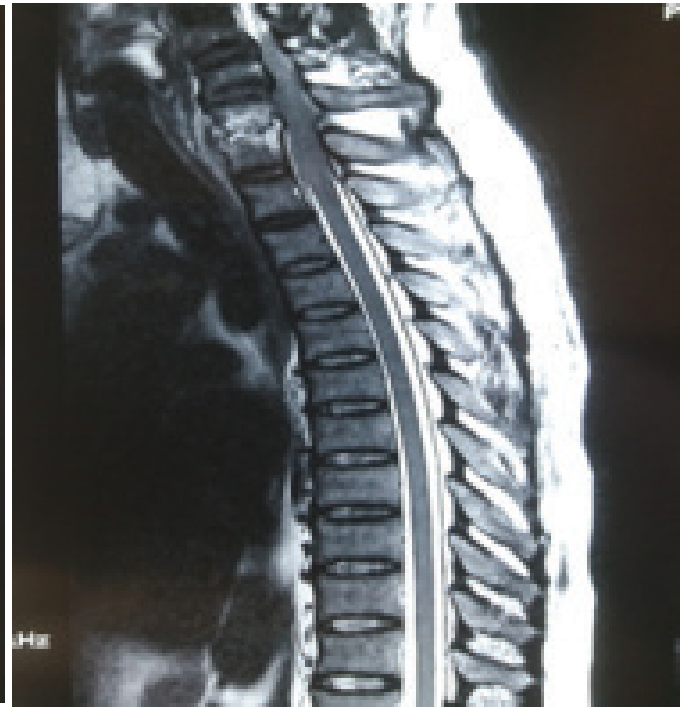

Fig.-3

CT guided FNAC from upper dorsal spine showed infiltration of inflammatory cells mostly neutrophils, edema and formation of granulation tissues. No evidence of granulomatous inflammation was found. No malignant cell was seen.

\section{Author Information}

a. Dr. Md. Rashedul Islam, MBBS, FCPS (Medicine), MRCP (UK), FACP(USA). Assistant Professor, Neurology, BIRDEM General Hospital, Shahbag, Dhaka, Bangladesh

b. Dr. SharifAhmed Khan, MBBS, MRCP(UK), Medical Officer, Neurology, BIRDEM General Hospital, Shahbag, Dhaka, Bangladesh

\section{Questions}

1. What are the findings in MRI of dorsal spine?

2. What is the most likely diagnosis?

3. Write down two differential diagnoses?

4. Mention specific treatment.

5. What are the Indications of surgery in this patient? 